\title{
Circulating DNA as biomarker in breast cancer
}

Heidi Schwarzenbach and Klaus Pantel

Abstract
As the release of tumor-associated DNA into blood
circulation is a common event in patients with cancer,
screening of plasma or serum DNA may provide
information on genetic and epigenetic profiles
associated with breast cancer development,
progression, and response to therapy. Quantitative
testing of circulating DNA can reflect tumor burden,
and molecular characterization of circulating DNA can
reveal important tumor characteristics relevant to the
choice of targeted therapies in individual patients.
Contrary to circulating DNA from blood that presents
molecular changes in tumor DNA in real time, tissue
biopsies can deliver only a spatially and temporally
limited snapshot of the heterogeneous tumor.
Analyses of circulating DNA might provide prognostic
and predictive information and therefore advance
personalized medicine. However, standardization of
different technical platforms as well as the control of
pre-analytical and analytical factors is mandatory
before its introduction into clinical practice. In the
present review, we discussed technical aspects and
clinical relevance of the analyses of circulating
plasma/serum DNA in patients with breast cancer.

\section{Introduction}

The presence of circulating, cell-free nucleic acids in the bloodstream was first described by Mandel and Métais in 1948 [1]. Thirty years later, Leon et al. showed that patients with breast cancer $(\mathrm{BC})$ display increased serum levels of cell-free DNA (cfDNA) in their blood circulation; they detected a wide DNA range, from 0 to $2000 \mathrm{ng} / \mathrm{ml}$, by radioimmunoassay [2]. In 1999, Silva et al. detected genetically altered and methylated cfDNA in the plasma of patients with $\mathrm{BC}[3-5]$. These observations led to

\footnotetext{
*Correspondence: pantel@uke.de

Department of Tumor Biology, University Medical Center

Hamburg-Eppendorf, Martinistraße 52, 20246 Hamburg, Germany
}

intensive quantitative and qualitative investigations of cfDNA in patients with BC.

The release of cfDNA into the bloodstream occurs by different sources, including the primary tumor, tumor cells that circulate in peripheral blood, metastatic deposits present at distant sites, and normal cell types, such as hematopoietic and stromal cells. Thus, both tumor and normal cfDNA circulate in the bloodstream of patients with cancer. Its rapidly increased accumulation in blood during tumor development is caused mainly by an excessive DNA release by apoptotic and necrotic cells. In addition, active secretion within exosomes has been demonstrated [6], but it is still discussed whether this is a relevant or rather minor source of cfDNA. The reduced clearance of cfDNA caused by impaired organ function during systemic inflammation may also contribute to cfDNA elevation in the blood of patients with cancer [7]. Because of the reduced cell turnover and more efficient removal of defect cells from the circulation by phagocytes, the concentrations of cfDNA are low in healthy individuals. Usually, cfDNA is removed from blood by liver and kidney, and its half-life is 10 to $15 \mathrm{~min}[8,9]$. The size of cfDNA may indicate its source. Apoptotic cells produce DNA fragments of 180-200 base pairs (bp) or multiples of this unit, whereas necrotic cells release higher molecular-weight DNA fragments of over 10,000 bp in size [10]. In patients with BC, cfDNA has also been analyzed in sources other than plasma and serum, such as urine [11]. Additionally, cfDNA species, such as cell-free mitochondrial DNA, are also under evaluation for clinical relevance [12].

In blood, cfDNA circulates predominantly as nucleosomes, which are nuclear complexes of histones and DNA [13]. They are frequently nonspecifically elevated in cancer but may be most valuable for monitoring cytotoxic cancer therapy, particularly for the early estimation of therapy efficacy. Combinations with other oncological or apoptotic biomarkers have been suggested to improve the sensitivity of detecting nonresponse to cytotoxic chemotherapy. Moreover, during neoadjuvant chemotherapy, $\mathrm{BC}$ patients with no change of disease had 
significantly higher pretherapeutic levels of circulating nucleosomes than patients in remission, indicating that apoptotic biomarkers bear valuable information for diagnosis and therapy response prediction [14].

$\mathrm{BC}$ is associated with different genetic and epigenetic events, such as DNA strand integrity, gene amplifications, gene mutations, DNA methylation, and microsatellite abnormalities. These alterations detected in the primary tumor may also be found in plasma/serum cfDNA of patients with $\mathrm{BC}$ (Table 1). In the present overview, we will concentrate mainly on recent progress in blood-based cfDNA analyses in BC.

\section{Techniques}

\section{Quantification}

cfDNA has been quantified by fluorescence-based methods, such as PicoGreen staining and ultraviolet spectrometry, or by the more sensitive quantitative polymerase chain reaction (PCR; SYBR Green or TaqMan) of repetitive elements or housekeeping genes [15]. Circulating nucleosomes, which are the primary repeating unit of DNA organization in chromatin, have usually been quantified by enzymelinked immunosorbent assays [13].

\section{Genetic analyses}

Microsatellite instability has routinely been assessed by using microsatellite-based fluorescence PCR. Mutations and copy number in cfDNA have been probed by using allele-specific PCR assays. However, for detection of rare mutations, more sensitive techniques, such as BEAMing (beads, emulsion, amplification and magnetics) or PAP (pyrophosphorolysis-activated polymerization), as well as digital genomic technologies adjusted with deep or nextgeneration sequencing DNA, are increasingly applied. A detailed overview of these technologies has been published elsewhere [16].

\section{Epigenetic analyses}

Aberrantly methylated cytosines within $\mathrm{CpG}$ dinucleotides can be detected by sodium bisulphite treatment of extracted cfDNA, which converts unmethylated cytosines to uracil. Techniques such as methylation-specific PCR, methyl-BEAMing, and quantum dot-based fluorescence resonance energy transfer (QD-FRET) have recently been adapted for the detection of methylated cfDNA (reviewed in [17]).

Table 2 summarizes the advantages and limitations of the currently used technologies to analyze cfDNA. However, these technical platforms differ in sensitivity and specificity, and their technical limitations to detect low levels of tumor cfDNA in an excess of wild-type DNA, as well as their sequence-specific bias, influence the results and consequently their comparability.

\section{cfDNA quantification and integrity}

The possibility of using plasma/serum cfDNA concentrations as an indicator of $\mathrm{BC}$ has been investigated by numerous studies [18]. Using fluorometry, Tangvarasittichai et al. showed the continuous increase in plasma cfDNA during tumor progression and its decrease after surgery. The median concentrations of plasma cfDNA were 0.5 , $235,422,1280$, and $0.5 \mathrm{ng} / \mathrm{ml}$ in BC patients classified by tumor stage I, II, III, and IV and surgical patients, respectively [19]. Huang et al. found that the median plasma DNA concentration $(65 \mathrm{ng} / \mathrm{ml})$ was significantly higher in patients with $\mathrm{BC}$ than in patients with benign breast diseases $(22 \mathrm{ng} / \mathrm{ml})$ or healthy women $(13 \mathrm{ng} / \mathrm{ml})$ [20]. A similar cfDNA elevation was documented by Kohler et al. They found that the cfDNA levels were significantly higher in patients with $\mathrm{BC}$ than in patients with benign diseases and healthy women, whereas the mitochondrial cfDNA levels were lower in both tumor cohorts [12]. In contrast, we found that although the serum cfDNA levels in patients with BC were significantly higher than in healthy women and were associated with a poor overall and disease-free survival, they could not discriminate malignant from benign breast lesions [21]. These discrepancies in the quantification of cfDNA may be explained by the use of plasma or serum and the different technical platforms, and emphasize that in the future a standardization of cfDNA measurements is essential.

Payne et al. [22] dealt with BC dormancy, the time between removal of the primary tumor and subsequent relapse of patients who have been clinically disease-free [23]. The authors quantified two overlapping cfDNA (96- and 291-bp) amplicons in the plasma of patients with BC. Increasing cfDNA concentrations correlated with estrogen receptor (ER), HER2, triple-negative tumors, and high tumor grade. Besides, an inverse relationship between mRNA of the epithelial marker cytokeratin 19 in bone marrow and the 291-bp amplicon in cfDNA was observed, suggesting that an inverse relationship between cell viability of disseminated tumor cells in bone marrow and cell death in plasma, respectively, occurs during the dormancy phase of BC [22].

Quantification of cfDNA has been extended to measurements of the integrity of cfDNA. Umetani et al. quantified the serum DNA integrity of short and long cfDNA fragments of noncoding $A L U$ repeat sequences, which are interspersed on chromosomes throughout the genome. Mean serum DNA integrity was significantly higher in patients with $\mathrm{BC}$ than in healthy women and was associated with lymphovascular invasion, lymph node metastasis, and tumor size. The receiver operating curve for discriminating lymph node status had an area under the curve (AUC) of 0.81 . These findings indicate that an $A L U$ DNA integrity assay is sensitive to detect early-stage metastasis to 
Table 1 Selected studies on circulating DNA in plasma and serum of patients with breast cancer

\begin{tabular}{|c|c|c|c|c|}
\hline$\underline{\text { Number of patients }}$ & Target of analysis & Methods & Clinical relevance & Reference \\
\hline \multirow[t]{3}{*}{$52 \mathrm{M0}, 26$ benign } & \multirow[t]{3}{*}{ Mitochondrial DNA quantification } & \multirow[t]{3}{*}{$\mathrm{qPCR}$} & Detection of cancer & \multirow[t]{3}{*}[12]{} \\
\hline & & & Deregulated DNA levels & \\
\hline & & & Diagnosis & \\
\hline \multirow[t]{2}{*}{$51 \mathrm{M0}, 28 \mathrm{M1}, 13$ benign } & \multirow[t]{2}{*}{ Nucleosome quantification } & \multirow[t]{2}{*}{ ELISA } & Monitoring for therapy response & \multirow[t]{2}{*}{ [14] } \\
\hline & & & Deregulated nucleosome levels & \\
\hline \multirow[t]{3}{*}{$31 \mathrm{M0}, 32 \mathrm{M1}, 20$ benign } & \multirow[t]{3}{*}{ DNA, nucleosome quantification } & \multirow[t]{3}{*}{ PicoGreen, ELISA } & Detection of cancer progression & \multirow[t]{3}{*}{ [13] } \\
\hline & & & Elevated nucleosome/DNA levels & \\
\hline & & & Diagnosis & \\
\hline \multirow[t]{2}{*}{$64 \mathrm{MO}$} & \multirow[t]{2}{*}{ DNA quantification } & \multirow[t]{2}{*}{$\mathrm{qPCR}$} & Monitoring for MRD & \multirow[t]{2}{*}[22]{} \\
\hline & & & Inverse relationship with DTC status & \\
\hline \multirow[t]{3}{*}{100 Stage I-IV } & \multirow[t]{3}{*}{ DNA quantification } & \multirow[t]{3}{*}{ Fluorometer } & Detection of cancer & \multirow[t]{3}{*}{ [19] } \\
\hline & & & Elevated DNA levels & \\
\hline & & & Diagnosis & \\
\hline \multirow[t]{3}{*}{$61 \mathrm{M0}, 33$ benign } & \multirow[t]{3}{*}{ DNA quantification } & \multirow[t]{3}{*}{$\mathrm{qPCR}$} & $\begin{array}{l}\text { Screening for early detection } \\
\text { and follow-up }\end{array}$ & \multirow[t]{3}{*}[20]{} \\
\hline & & & Deregulated DNA levels & \\
\hline & & & Diagnosis & \\
\hline \multirow[t]{2}{*}{$83 \mathrm{M0}$} & \multirow[t]{2}{*}{ DNA integrity } & qPCR & Detection of cancer progression & [24] \\
\hline & & & Diagnosis & \\
\hline $65 \mathrm{M0}, 47 \mathrm{M1}, 12$ benign & DNA integrity & $\mathrm{qPCR}$ & Detection of cancer & {$[25]$} \\
\hline & & & Diagnosis & \\
\hline 82 M0, 201 M1 & DNA integrity & $q P C R$ & Detection of cancer & {$[26]$} \\
\hline & & & $\begin{array}{l}\text { Correlation with progression-free } \\
\text { and overall survival }\end{array}$ & \\
\hline & & & Diagnosis and prognosis & \\
\hline $65 \mathrm{M0}$ & DNA integrity & $\mathrm{qPCR}$ & Monitoring for therapy response & {$[27]$} \\
\hline $25 \mathrm{MO}$ & Mutations & PCR-SSCP and & Detection of cancer & {$[5]$} \\
\hline & & & Diagnosis & \\
\hline $313 \mathrm{MO}$ & Mutations & Digital PCR & $\begin{array}{l}\text { Correlation with recurrence-free } \\
\text { and overall survival }\end{array}$ & [33] \\
\hline & & & Prognosis & \\
\hline $17 \mathrm{M} 1$ & Mutations & Next-generation sequencing & Detection of metastasis & [34] \\
\hline & & & Diagnosis & \\
\hline $33 \mathrm{MO}$ & Mutations & Digital PCR & Detection of cancer & {$[35]$} \\
\hline & & & Diagnosis & \\
\hline $30 \mathrm{M} 1$ & Mutations & Targeted sequencing & Detection of metastasis & {$[36]$} \\
\hline & & & Monitoring for therapy response & \\
\hline $2 \mathrm{MO}$ & Mutations & Whole exome sequencing & $\begin{array}{l}\text { Detection of acquired drug } \\
\text { resistance in advanced cancer }\end{array}$ & [37] \\
\hline $65 \mathrm{M0}$ & SNP/CNV & Array & $\begin{array}{l}\text { Detection of cancer during } \\
\text { routine follow-up }\end{array}$ & [31] \\
\hline & & & Correlation with MRD & \\
\hline & & & Diagnosis & \\
\hline $58 \mathrm{M} 1$ & Copy number & Whole-genome sequencing & $\begin{array}{l}\text { Dynamic variation of DNA range } \\
\text { in metastasis }\end{array}$ & {$[38]$} \\
\hline $65 \mathrm{M0}, 58 \mathrm{M1}$ & Copy number & Digital PCR & $\begin{array}{l}\text { Screening for the acquisition of } \\
\text { HER2 amplification in metastasis }\end{array}$ & [29] \\
\hline
\end{tabular}


Table 1 Selected studies on circulating DNA in plasma and serum of patients with breast cancer (Continued)

\begin{tabular}{|c|c|c|c|c|}
\hline \multirow[t]{2}{*}{$102 \mathrm{M0}, 32$ benign } & \multirow[t]{2}{*}{$\mathrm{LOH}$} & \multirow[t]{2}{*}{$P C R$} & $\begin{array}{l}\text { Correlation with overall and } \\
\text { disease-free survival }\end{array}$ & \multirow[t]{2}{*}{21} \\
\hline & & & Diagnosis and prognosis & \\
\hline \multirow[t]{2}{*}{$62 \mathrm{M0}$} & \multirow[t]{2}{*}{ LOH, Methylation, Mutations } & \multirow{2}{*}{$\begin{array}{l}\text { Microsatellite, } \\
\text { PCR-SSCP, MSP }\end{array}$} & Detection of tumor progression & \multirow[t]{2}{*}{ [3] } \\
\hline & & & Diagnosis & \\
\hline \multirow[t]{2}{*}{$35 \mathrm{M0}$} & \multirow[t]{2}{*}{ Methylation } & \multirow[t]{2}{*}{ MSP } & Detection of cancer & \multirow[t]{2}{*}{ [4] } \\
\hline & & & Diagnosis & \\
\hline \multirow[t]{2}{*}{$428 \mathrm{MO}$} & \multirow[t]{2}{*}{ Methylation } & \multirow[t]{2}{*}{ MethyLight PCR } & $\begin{array}{l}\text { Correlation with overall } \\
\text { and disease-free survival }\end{array}$ & \multirow[t]{2}{*}{39} \\
\hline & & & Therapy-independent prognosis & \\
\hline \multirow[t]{2}{*}{$101 \mathrm{M0}, 58 \mathrm{M1}$} & \multirow[t]{2}{*}{ Methylation } & \multirow[t]{2}{*}{ OS-MSP } & Detection of metastasis & \multirow[t]{2}{*}{ [40] } \\
\hline & & & Diagnosis & \\
\hline \multirow[t]{2}{*}{$336 \mathrm{MO}$} & \multirow[t]{2}{*}{ Methylation } & \multirow[t]{2}{*}{ OS-MSP } & Correlation with overall survival & \multirow[t]{2}{*}{ [41] } \\
\hline & & & Prognosis & \\
\hline $80 \mathrm{M} 1$ & Methylation & MSP & Correlation with CTC status & [42] \\
\hline $148 \mathrm{MO}$ & Methylation & MethyLight PCR & Monitoring for therapy response & [43] \\
\hline $52 \mathrm{MO}$ & Methylation & MSP & Monitoring for therapy response & [44] \\
\hline $110 \mathrm{MO}$ & Methylation & MSP & $\begin{array}{l}\text { Detection of estrogen } \\
\text { receptor-negative status }\end{array}$ & [45] \\
\hline \multirow[t]{2}{*}{120 M0, 100 benign } & \multirow[t]{2}{*}{ Methylation } & \multirow[t]{2}{*}{ MSP } & Detection of cancer & \multirow[t]{2}{*}{ [46] } \\
\hline & & & Diagnosis & \\
\hline \multirow[t]{3}{*}{$155 \mathrm{MO}$} & \multirow[t]{3}{*}{ Methylation } & \multirow[t]{3}{*}{ MSP } & Detection of metastasis & \multirow[t]{3}{*}{47} \\
\hline & & & $\begin{array}{l}\text { Correlation with overall and } \\
\text { disease-free survival }\end{array}$ & \\
\hline & & & Diagnosis and prognosis & \\
\hline \multirow[t]{2}{*}{$79 \mathrm{MO}$} & Methylation & MSP & Correlation with CTC status & [48] \\
\hline & & & Diagnosis & \\
\hline $100 \mathrm{MO}$ & Methylation & MSP & Correlation with protein expression & [50] \\
\hline & & & Diagnosis & \\
\hline $203 \mathrm{MO}$ & Methylation & MSP & Association with DNA repair capacity & [51] \\
\hline & & & Diagnosis & \\
\hline 304 M0 234 benign & Methylation & Pyrosequencing & $\begin{array}{l}\text { Modest difference in methylation } \\
\text { patterned }\end{array}$ & [52] \\
\hline
\end{tabular}

This table represents a selection of cell-free DNA analyses in plasma or serum of patients with breast cancer and is not meant to be comprehensive. It is based on our own view of studies that offer substantial clinical insight

CNV copy number variation, CTC circulating tumor cell, DTC disseminated tumor cell, ELISA enzyme-linked immunosorbent assay, HER2 human epidermal growth factor receptor 2, $L O H$ loss of heterozygosity, $M O$ patients with primary breast cancer, $M 1$ patients with metastatic breast cancer, MRD minimal residual disease, MSP methylation-specific polymerase chain reaction, OS-MSP one-step methylation-specific polymerase chain reaction, $P C R$-SSCP polymerase chain reaction-single strand conformation polymorphism, $q P C R$ quantitative real-time polymerase chain reaction, $S N P$ single-nucleotide polymorphism

regional tumor-draining lymph nodes [24]. Stotzer et al. demonstrated that plasma cfDNA is rather valuable for the detection of locally confined $\mathrm{BC}$ but that the established tumor markers are most informative in metastatic BC [25]. Discrimination of locally confined $\mathrm{BC}$ from healthy controls was achieved by ALU115 (AUC of 95.4) and ALU247 (AUC of 95.5) and of metastatic $\mathrm{BC}$ from both benign controls and locally confined BC by CA15-3 (AUC of 83.2) and CEA (AUC of 79.1). Moreover, Madhavan et al. determined plasma
cfDNA concentrations and cfDNA integrity of $A L U$ and LINE1 repetitive DNA elements [26]. A hierarchical decrease in cfDNA integrity and increase in cfDNA concentrations from healthy controls over primary $\mathrm{BC}$ and further to patients with metastatic BC were observed. Combination of cfDNA integrity and concentrations could differentiate controls from primary BC cases (AUC of 0.75), circulating tumor cell (CTC)-negative metastatic cases (AUC of 0.81), and CTC-positive metastatic BC (AUC of 0.93) as well as CTC-negative from CTC-positive 
Table 2 Commonly used technologies to analyze cell-free DNA

\begin{tabular}{lll}
\hline Technique & Advantages & Limitations \\
\hline Quantitative PCR & High sensitivity and specificity & Quantification of only annotated sequences \\
BEAMing, PAP, COBRA, etc. & High dynamic range & \\
& Higher sensitivity and specificity than quantitative PCR & Analyses of only predetermined sequences \\
& Detection of at least $0.01 \%$ altered alleles & \\
Microarray & High throughput & Not suitable for accurate quantification \\
& Relatively low cost & Low dynamic range \\
& Detection of only annotated DNA & High signal-to-noise ratio \\
Next-generation sequencing & Cross-hybridization between similar sequences & \\
& High sensitivity and specificity & High cost \\
& Detection of novel and rare alterations & Need for special equipment and bioinformatics \\
& Ability to distinguish similar sequences & Relatively high amounts of starting material \\
\hline
\end{tabular}

$P C R$ polymerase chain reaction, BEAMing beads, emulsion, amplification and magnetics, $P A P$ pyrophosphorolysis-activated polymerization, COBRA combined bisulfite restriction analysis

metastatic BC cases (AUC of 0.83). The cfDNA integrity was additionally associated with progression-free and overall survival of patients with metastatic BC and had a lower prediction error than the CTC status [26].

cfDNA measurements have also been carried out in $\mathrm{BC}$ patients undergoing chemotherapy. Patients with large or nonoperable $\mathrm{BC}$ often receive neoadjuvant chemotherapy to facilitate full resection of the tumor and enable conservation of breast. Lehner et al. quantified the levels of repetitive ALU115 and ALU247 elements in such patients with BC before surgery and found that the pretherapeutic HER2 status was positively correlated with therapy response [27]. From therapy cycle 1 to 6 , the kinetics of ALU115 showed decreases in patients with complete remission, whereas in patients with no change of disease, an increase was observed. Similar tendencies were obtained for ALU247 fragments, whereas CEA and CA15-3 were not informative for therapy outcome.

The studies described above are not claimed to be comprehensive, but they provide insight into the clinical relevance of cfDNA levels and integrity in different populations of patients with $\mathrm{BC}$. They demonstrate that their quantifications may serve as a diagnostic, prognostic, and predictive marker for $\mathrm{BC}$. However, the increase in cfDNA levels is not cancer-specific, because their changes can also be observed in other cancer types. Moreover, their values can overlap between benign and malignant diseases. Therefore, these measurements may be rather useful in combination with other blood tumor biomarkers.

\section{Genetic analyses}

Microsatellite instability, such as loss of heterozygosity $(\mathrm{LOH})$, is frequently found in tumor tissues. To date, $\mathrm{LOH}$ has also been detected in plasma or serum cfDNA and its frequency correlated with diagnosis and prognosis in patients with BC (reviewed in [18]). Recently, however, the interest in analyzing $\mathrm{LOH}$ in cfDNA has decreased because, owing to the high background of normal cfDNA in blood, the $\mathrm{LOH}$ frequency was usually low. Owing to inflammation or tissue repair processes, leukocytes and stroma cells, as well as the abnormal proliferation of benign cells, contribute to the accumulation of normal wild-type DNA in blood. The proportion of wild-type DNA in the blood circulation of patients with $\mathrm{BC}$ is unknown and may fluctuate. Therefore, only a small fraction of cfDNA is tumor-derived (reviewed in [18]).

At present, in the scientific community, there is an increased focus on the analyses of cfDNA copy number and mutations using new technical platforms (reviewed in [28]). In this regard, digital PCR was adapted to determine the presence of HER2 copy number in plasma cfDNA. Using this approach, Gevensleben et al. showed that the plasma cfDNA copy number ratio of HER2 to a reference gene had an AUC of 0.92 and that $64 \%$ of patients with HER2-amplified cancer and $94 \%$ of patients with HER2-nonamplified cancer displayed positive and negative predictive values of $70 \%$ and $92 \%$, respectively [29].

In disease relapse and formation of metastases, minimal residual disease (MRD), usually analyzed by CTCs, plays a major role [30]. To monitor MRD by copy number variations, Shaw et al. profiled 251 genomes using Affymetrix genome-wide human single-nucleotide polymorphism arrays [31]. In paired cfDNA and primary tumor samples, focal high-level DNA amplifications clustered in numerous chromosome arms, some of which harbored genes with oncogenic potential, including USP17L2 (DUB3), $B R F 1, M T A 1$, and JAG2, were identified. Up to 12 years after diagnosis, these amplifications were still detectable in 
some of the follow-up plasma samples. These cfDNA array analyses could distinguish between preoperative $\mathrm{BC}$ patients and those who have had surgery and treatment.

In ER-positive $\mathrm{BC}$, mutations of PIK3CA are the most frequent genomic alterations. They lead to activation of the phosphoinositide 3-kinase (PI3K) signaling pathway that plays a central role in cellular processes, such as cell survival, growth, division, and motility [32]. Applying a digital PCR assay, Oshiro et al. detected that serum samples from $23 \%$ of PIK3CA-mutant patients were positive for this mutation [33]. No PIK3CA-mutant cfDNA was detected in the serum samples of PIK3CAnonmutant $\mathrm{BC}$ patients and healthy women. The dichotomization of patients into PIK3CA-mutant subgroups with high and low cfDNA levels showed that the mutant cfDNA-high level subgroup exhibited significantly shorter recurrence-free and overall survival rates than the cfDNAlow level subgroup and nonmutant patient group, indicating that PIK3CA mutation status is a significant and independent prognostic factor for patients with $\mathrm{BC}$ [33].

However, the detection rate of mutations is higher if the new technique of next-generation sequencing (NGS) is applied. When plasma samples were analyzed by Rothe et al., 12 of 17 patients had more than one mutation in p53, PIK3CA, PTEN, AKT1, IDH2, or SMAD4. In 13 of 17 patients, plasma and tumor tissue samples provided concordant results, whereas the four other discordant cases provided complementary information [34]. Bettegowda et al. used whole-genome sequencing and detected tumor cfDNA in the plasma of more than $75 \%$ of advanced BC and $50 \%$ of localized $\mathrm{BC}$ patients [35]. The frequent presence of tumor cfDNA in BC patients without detectable CTCs suggests that these two circulating biomarkers are distinct entities.

Finally, using targeted or whole-genome sequencing, the laboratory of Caldas and Rosenfeld identified somatic genomic alterations in serially collected plasma from patients with metastatic BC [36]. Tumor-associated cfDNA was detected in $97 \%$ of BC patients in whom somatic genomic alterations were identified, whereas the tumor marker CA15-3 and CTCs were detected in $78 \%$ and $87 \%$ of the patients, respectively. The tumor cfDNA levels showed a greater dynamic range, and greater correlation with changes in tumor burden, than did CA15-3 or CTCs detected by the CellSearch system. It should be mentioned that, despite the ground-breaking nature of this study, the dropout rate was considerable and the analyses were restricted to a small cohort of patients. Therefore, these results need further validation. The same group also massively parallel sequenced cancer exomes in serial plasma samples to track genomic evolution of metastatic BC in response to therapy. Quantification of allele fractions in plasma identified increased representation of mutant alleles in association with acquired drug resistance. These included an activating mutation in PIK3CA following treatment with paclitaxel, a truncating mutation in the ER co-activator MED1 (mediator complex subunit 1) following treatment with tamoxifen and trastuzumab and following subsequent treatment with lapatinib, a splicing mutation in GAS6, the ligand for the tyrosine kinase receptor AXL, in the same patient [37].

To sum up, the inconsistent detection of mutations in cfDNA by the earlier studies could be improved by advanced genomic approaches that have higher sensitivity to identify rare mutations in matched cfDNA and tumor tissue samples. However, the study by Heidary et al. exemplified that cfDNA content may not always reflect the actual stage of disease progression [38]. Although all patients had progressive metastatic disease, plasma analyses demonstrated highly variable allele fractions of mutant fragments. The allele fractions of cfDNA were only $2-3 \%$, neither reflecting the tumor burden nor the dynamics of the disease, whereas the number of CTCs was exceedingly high, indicating that analysis of cfDNA and CTCs provides complementary information. The variable presence of mutated plasma cfDNA, together with high-resolution fragment sizing, was explained by differences in phagocytosis and DNA degradation mechanisms [38]. Moreover, progressing metastatic lesions consist mainly of viable cells and may have only a small fraction of apoptotic cells that are able to release DNA into the circulation.

\section{Epigenetic analyses}

Aberrant DNA methylation is thought to be associated with an increased risk for neoplastic transformation. By the hypermethylation of CpG-rich regions in their promoter region, tumor suppressor genes become inactivated. Although such epigenetic alterations are not unique for $\mathrm{BC}$, there are tumor suppressor genes that are frequently methylated and downregulated in $\mathrm{BC}$. A phenotypic feature of $\mathrm{BC}$ biology is methylated RASSF1A. Its aberrant promoter hypermethylation may be common among high-risk women, leading to the repression of this scaffold protein that localizes signaling in cells. Gobel et al. investigated the methylation status of RASSF1A together with PITX2 in the blood plasma and bone marrow plasma of patients with $\mathrm{BC}$ by using MethyLight, a quantitative methylation-specific PCR method [39]. Methylated RASSF1A and PITX2 detected in blood plasma were significant indicators for poor overall survival and distant disease-free survival, whereas in bone marrow plasma only methylated RASSF1A had a prognostic value. Yamamoto et al. showed that the sensitivity of detection of methylation in RASSF1A, GSTP1, or RARß2 (or a combination of these genes) in the serum of patients with primary and 
metastatic $\mathrm{BC}$ was significantly higher than that involving CEA or CA15-3 [40]. When the assay was combined with these conventional tumor markers, the sensitivity increased to $78 \%$. Fujita et al. showed that $10 \%$ of patients were positive for methylated serum cfDNA of these three genes and also had a significantly worse overall survival rate at 100 months in comparison with those with negative findings [41]. When combined with the levels of total serum DNA, these methylated cfDNA concentrations were even more effective for prediction of prognosis for patients with BC. Furthermore, Van der Auwera et al. demonstrated that detection of methylated RASSF1A (29\%), adenomatous polyposis coli (APC) (35\%), or ER1 (20\%) correlated with the number of CTCs, enumerated by the CellSearch System, and thus indicates the CTC status in patients with metastatic BC [42].

Detection of methylated RASSF1 in blood may also monitor response during chemotherapy. The methylation status of RASSF1A has also been investigated under chemotherapy. In this regard, Fiegl et al. demonstrated that RASSF1A methylation is an independent predictor of poor outcome for patients with BC [43]. The authors analyzed RASSF1A methylation in $\mathrm{BC}$ patients who received adjuvant tamoxifen. In their serum samples before therapy and 1 year after surgery, $19.6 \%$ and $22.3 \%$ of patients with $\mathrm{BC}$ harbored RASSF1A methylation, respectively. Disappearance of RASSF1A methylation in the serum throughout treatment with tamoxifen indicated response, whereas its persistence or new appearance meant resistance to adjuvant tamoxifen treatment. In the pilot study by Avraham et al., consecutive serum samples from 52 patients with locally advanced BC were analyzed for RASSF1 methylation during neoadjuvant chemotherapy [44]. Methylated RASSF1 was detected in the serum of $40 \%$ of patients before therapy. In $8 \%$ of patients who achieved complete pathological response, RASSF1 methylation became undetectable in the serum early during therapy. In contrast, in $33 \%$ of patients who had partial or minimal pathological response, RASSF1 methylation persisted in the serum longer or throughout the treatment, respectively [44].

$E R$ status is an important predictive marker, and its loss leads to the resistance to endocrine treatment in patients with BC. In this regard, Martinez-Galan et al. explored the relationship between ER expression in tumor tissue and methylation of the $E R$ promoter region in plasma [45]. A significant association between methylated $E R$ in cfDNA and ER-negative status was detected, indicating silencing by methylation of $E R$ in $\mathrm{BC}$. In the study by Hagrass et al., three different markers (ER3, ER4, and ER5) were used to analyze methylation status of the $E R \alpha$ promoter region in serum and tumor tissue samples [46]. The rates of methylation status of $E R 3, E R 4$, and $E R 5$ were $65 \%, 26.7 \%$, and $61.7 \%$ in tumor tissue, respectively, and $57.5 \%, 21.7 \%$, and $55.8 \%$ in serum, respectively, indicating the lower frequency of DNA methylation in serum. The rates of concordance between tumor and serum DNA methylation were $80 \%, 72 \%$, and $92 \%$ for $E R 3, E R 4$, and $E R 5$, respectively, suggesting that methylated DNA is released mainly by the primary tumor.

The transcription factor Sox17 is involved in a variety of developmental processes and can act as an antagonist of the canonical Wnt/beta-catenin signaling pathway. Fu et al. examined the methylation status of Sox17 in paired $\mathrm{BC}$ tissue and plasma samples [47]. The frequencies of Sox 17 methylation were $72.9 \%$ in BC tissues and $58.1 \%$ in plasma cfDNA. Methylated Sox17 was not found in normal breast tissues and plasma samples. The significant correlation of Sox17 methylation between tumor tissues and paired plasma was associated with tumor node metastasis stage, lymph node metastasis, poor disease-free survival, and overall survival, indicating that Sox17 methylation may be an independent diagnostic and prognostic factor for BC. Chimonidou et al. found a relationship of this highly methylated gene with the presence of CTCs in BC patients after surgical removal of the primary tumor [48]. The SOX17 promoter was methylated in $86.0 \%$ of tumor tissues. In CTCs, SOX17 was methylated in $34.5 \%$ of patients with early BC, $45.8 \%$ of patients with metastatic cancer, and one healthy woman, whereas in matched plasma cfDNA samples, SOX17 was methylated in $34.5 \%, 40.7 \%$, and one of the corresponding individuals, respectively. There was a significant correlation between SOX17 methylation in cfDNA and CTCs in patients with early BC but not in patients with metastatic $\mathrm{BC}$. These findings suggest that CTCs contribute to the release of DNA into the blood circulation. The discordance between SOX17 methylation in CTCs and cfDNA methylation in patients with metastatic BC may be due to the release of DNA from apoptotic cells escaping from metastatic deposits at distant sites, such as bone marrow and liver [48].

Maspin, a noninhibitory member of the serine protease inhibitor superfamily, inhibits cancer cell invasion, attachment to extracellular matrices, and angiogenesis and increases sensitivity to apoptosis. However, whereas experimental data support the role of Maspin as a tumor suppressor, clinical data regarding its prognostic implications have led to conflicting results [49]. Sharma et al. examined its promoter methylation status in tumor tissue and matched serum samples of patients with invasive ductal BC [50]. Immunohistochemistry displayed loss of Maspin protein expression in tumor tissue that was significantly associated with methylated Maspin in paired serum samples. Dysregulation of DNA repair capacity is a further genetic risk factor for $\mathrm{BC}$ that has usually been measured in lymphocytes. In a BC casecontrol project, Guerrero-Preston et al., who analyzed 
the plasma levels of promoter methylation of $K I F 1 A$, $M A L, F K B P 4, V G F$, and $O G D H$, found an inverse association of DNA repair capacity with promoter methylation of the kinesin motor protein KIF1A in plasma [51]. This was the first evidence of an association between genetic and epigenetic alterations in $\mathrm{BC}$ using blood-based tests.

In contrast to these encouraging studies, Sturgeon et al. found only insufficient differences in DNA methylation between $\mathrm{BC}$ cases and controls [52]. The objective of their study was to evaluate promoter methylation of a panel of 12 BC-related genes (APC, BRCA1, CCND2, CDH1, ER1, GSTP1, HIN1, P16, RAR $\beta$, RASSF1, SFRP1, and TWIST) in the serum of postmenopausal women, including $\mathrm{BC}$ cases with lymph node-positive disease, $\mathrm{BC}$ cases with lymph node-negative disease, and women with benign breast diseases. For all genes in each study group, the median levels of promoter methylation were low, typically below $5 \%$, but higher in lymph nodepositive $\mathrm{BC}$ cases than in the controls. These findings demonstrate that, although there is growing evidence that methylated tumor suppressor genes in plasma/ serum are promising biomarkers for $\mathrm{BC}$, it is worth keeping in mind that the methylation frequency is usually lower in plasma/serum than in tumor tissues.

\section{Conclusions}

The current studies show that quantitative and qualitative tumor-associated changes in genetic and epigenetic profiles may correlate with the biological behavior and response to therapy of $\mathrm{BC}$. At present, there is a great heterogeneity amongst the cfDNA data in different studies using plasma or serum, different technical platforms and patient populations (Tables 1 and 2). Thus, a standardization of cfDNA analyses in terms of sample collection, processing, and molecular techniques is required. Then, these protocols can be validated in well-designed prospective patient cohorts providing sufficient power and sample size. Expected results could be the establishment of a multivariate risk model based on traditional clinical factors and assessment of cfDNA signatures as well as the development of companion diagnostics for targeted therapies.

Before implementation of cfDNA analysis into the clinical decision, several issues need to be addressed in future studies: (i) Because cfDNA represents mainly the genome of dying tumor cells, the time point of blood sampling during the course of a treatment is important to discover genetic alterations present in the resistant tumor cell clones. (ii) Genomic screening using NGS technologies has made enormous advances but has also led to the discovery of many genomic aberrations without known clinical relevance. Thus, clinical intervention studies with established endpoints (e.g., overall survival) in which decisions are made on the basis of cfDNA analysis are needed to demonstrate that the patient will benefit from cfDNA measurements. (iii) Masking of ctDNA by variable amounts of normal cfDNA released by dying normal cells (e.g., during chemotherapy, surgery, infections) might lead to false-negative results. (iv) Many individuals have benign tumors (e.g., skin tumors) that carry cancer-associated mutations and that may cause false-positive findings for cancer screening. Thus, the use of cfDNA analysis for primary detection of cancer requires very large cohorts of patients with cancer, and matched control individuals need to be analyzed prospectively over extended periods of time ( $>10$ years). A possible way to circumvent this problem could be the focus on patients at high risk to develop cancer.

\section{Abbreviations}

APC: Adenomatous polyposis coli; AUC: Area under curve; BC: Breast cancer; BEAMing: Beads, emulsion, amplification and magnetics; bp: Base pair; BRCA1: Breast cancer 1; BRF1: TFIIB-related factor; CCND2: Cyclin D2; CDKN2A (p16): Cyclin-dependent kinase inhibitor; cfDNA: Cell-free DNA; CTC: Circulating tumor cell; DUB3: Deubiquitylase; ER: Estrogen receptor; FKBP4: FK binding protein 4; GAS6: Growth arrest-specific 6; GSTP1: Glutathione S-transferase P1; HER2: Human epidermal growth factor receptor; HIN1: Hairpin induced gene 1; IDH2: Isocitrate dehydrogenase 2; JAG2: Jagged 2; KIF1A: Kinesin family member 1a; LOH: Loss of heterozygosity; MAL: Myelin and lymphocyte protein; Maspin: Mammary serine protease inhibitor; MRD: Minimal residual disease; MTA1: Metastatic tumor antigen 1; NGS: Next-generation sequencing; OGDH: Oxoglutarate dehydrogenase; PCR: Polymerase chain reaction; PIK3CA: Phosphatidylinositol-3 kinase (PI3K) catalytic subunit; PITX2: Pituitary homeobox 2; PTEN: Phosphatase and tensin homolog; RARß: Retinoic acid receptor $\beta$; RASSF1A: Ras association domain family protein 1A; SFRP1: Secreted frizzled-related protein 1 .

\section{Competing interests}

The authors declare that they have no competing interests.

\section{Authors' contributions}

$\mathrm{HS}$ and KP conceived, designed, and wrote the manuscript. Both authors read and approved the final manuscript.

Published online: 09 October 2015

\section{References}

1. Mandel P, Métais P. Les acides nucléiques du plasma sanguin chez l'homme (Nucleic acids in human blood plasma). C R Acad Sci Paris. 1948;142:241-3.

2. Leon SA, Shapiro B, Sklaroff DM, Yaros MJ. Free DNA in the serum of cancer patients and the effect of therapy. Cancer Res. 1977;37:646-50.

3. Silva JM, Dominguez G, Garcia JM, Gonzalez R, Villanueva MJ, Navarro F, et al. Presence of tumor DNA in plasma of breast cancer patients: clinicopathological correlations. Cancer Res. 1999;59:3251-6.

4. Silva JM, Dominguez G, Villanueva MJ, Gonzalez R, Garcia JM, Corbacho C, et al. Aberrant DNA methylation of the p16INK4a gene in plasma DNA of breast cancer patients. Br J Cancer. 1999;80:1262-4.

5. Silva JM, Gonzalez R, Dominguez G, Garcia JM, Espana P, Bonilla F. TP53 gene mutations in plasma DNA of cancer patients. Genes Chromosomes Cancer. 1999;24:160-1.

6. Thakur BK, Zhang H, Becker A, Matei I, Huang Y, Costa-Silva B, et al. Double-stranded DNA in exosomes: a novel biomarker in cancer detection. Cell Res. 2014;24:766-9.

7. Stroun M, Lyautey J, Lederrey C, Olson-Sand A, Anker P. About the possible origin and mechanism of circulating DNA apoptosis and active DNA release. Clin Chim Acta. 2001;313:139-42.

8. Rumore P, Muralidhar B, Lin M, Lai C, Steinman CR. Haemodialysis as a model for studying endogenous plasma DNA: oligonucleosome-like structure and clearance. Clin Exp Immunol. 1992;90:56-62. 
9. Schwarzenbach $H$, Hoon DS, Pantel K. Cell-free nucleic acids as biomarkers in cancer patients. Nat Rev Cancer. 2011;11:426-37.

10. Jahr S, Hentze H, Englisch S, Hardt D, Fackelmayer FO, Hesch RD, et al. DNA fragments in the blood plasma of cancer patients: quantitations and evidence for their origin from apoptotic and necrotic cells. Cancer Res. 2001;61:1659-65.

11. Bryzgunova OE, Skvortsova TE, Kolesnikova EV, Starikov AV, Rykova EY, Vlassov W, et al. Isolation and comparative study of cell-free nucleic acids from human urine. Ann N Y Acad Sci. 2006;1075:334-40.

12. Kohler C, Radpour R, Barekati Z, Asadollahi R, Bitzer J, Wight E, et al. Levels of plasma circulating cell free nuclear and mitochondrial DNA as potential biomarkers for breast tumors. Mol Cancer. 2009;8:105.

13. Roth C, Pantel K, Muller V, Rack B, Kasimir-Bauer S, Janni W, et al. Apoptosis-related deregulation of proteolytic activities and high serum levels of circulating nucleosomes and DNA in blood correlate with breast cancer progression. BMC Cancer. 2011;11:4.

14. Stoetzer OJ, Fersching DM, Salat C, Steinkohl O, Gabka CJ, Hamann U, et al. Prediction of response to neoadjuvant chemotherapy in breast cancer patients by circulating apoptotic biomarkers nucleosomes, DNAse, cytokeratin-18 fragments and survivin. Cancer Lett. 2013;336:140-8.

15. Pinzani P, Salvianti F, Pazzagli M, Orlando C. Circulating nucleic acids in cancer and pregnancy. Methods. 2010;50:302-7.

16. Benesova L, Belsanova B, Suchanek S, Kopeckova M, Minarikova P, Lipska L, et al. Mutation-based detection and monitoring of cell-free tumor DNA in peripheral blood of cancer patients. Anal Biochem. 2013;433:227-34.

17. Wittenberger T, Sleigh S, Reisel D, Zikan M, Wahl B, Alunni-Fabbroni M, et al. DNA methylation markers for early detection of women's cancer: promise and challenges. Epigenomics. 2014;6:311-27.

18. Schwarzenbach $\mathrm{H}$. Circulating nucleic acids as biomarkers in breast cancer. Breast Cancer Res. 2013;15:211.

19. Tangvarasittichai O, Jaiwang W, Tangvarasittichai S. The plasma DNA concentration as a potential breast cancer screening marker. Indian J Clin Biochem. 2015;30:55-8

20. Huang ZH, Li LH, Hua D. Quantitative analysis of plasma circulating DNA at diagnosis and during follow-up of breast cancer patients. Cancer Lett. 2006;243:64-70.

21. Schwarzenbach $H$, Muller V, Milde-Langosch K, Steinbach B, Pantel K. Evaluation of cell-free tumour DNA and RNA in patients with breast cancer and benign breast disease. Mol Biosyst. 2011;7:2848-54

22. Payne RE, Hava NL, Page K, Blighe K, Ward B, Slade M, et al. The presence of disseminated tumour cells in the bone marrow is inversely related to circulating free DNA in plasma in breast cancer dormancy. Br J Cancer. 2012;106:375-82.

23. Klein CA, Holzel D. Systemic cancer progression and tumor dormancy: mathematical models meet single cell genomics. Cell Cycle. 2006;5:1788-98.

24. Umetani N, Giuliano AE, Hiramatsu SH, Amersi F, Nakagawa T, Martino S, et al. Prediction of breast tumor progression by integrity of free circulating DNA in serum. J Clin Oncol. 2006;24:4270-6.

25. Stotzer OJ, Lehner J, Fersching-Gierlich D, Nagel D, Holdenrieder S. Diagnostic relevance of plasma DNA and DNA integrity for breast cancer. Tumour Biol. 2014;35:1183-91.

26. Madhavan D, Wallwiener M, Bents K, Zucknick M, Nees J, Schott S, et al. Plasma DNA integrity as a biomarker for primary and metastatic breast cancer and potential marker for early diagnosis. Breast Cancer Res Treat. 2014;146:163-74.

27. Lehner J, Stotzer OJ, Fersching D, Nagel D, Holdenrieder S. Circulating plasma DNA and DNA integrity in breast cancer patients undergoing neoadjuvant chemotherapy. Clin Chim Acta. 2013;425:206-11.

28. Diaz Jr LA, Bardelli A. Liquid biopsies: genotyping circulating tumor DNA J Clin Oncol. 2014;32:579-86

29. Gevensleben H, Garcia-Murillas I, Graeser MK, Schiavon G, Osin P, Parton M, et al. Noninvasive detection of HER2 amplification with plasma DNA digital PCR. Clin Cancer Res. 2013;19:3276-84.

30. Alix-Panabieres C, Schwarzenbach H, Pantel K. Circulating tumor cells and circulating tumor DNA. Annu Rev Med. 2012;63:199-215.

31. Shaw JA, Page K, Blighe K, Hava N, Guttery D, Ward B, et al. Genomic analysis of circulating cell-free DNA infers breast cancer dormancy. Genome Res. 2012;22:220-31.

32. Bosch A, Li Z, Bergamaschi A, Ellis H, Toska E, Prat A, et al. PI3K inhibition results in enhanced estrogen receptor function and dependence in hormone receptor-positive breast cancer. Sci Transl Med. 2015;7:283ra251.

33. Oshiro C, Kagara N, Naoi Y, Shimoda M, Shimomura A, Maruyama N, et al. PIK3CA mutations in serum DNA are predictive of recurrence in primary breast cancer patients. Breast Cancer Res Treat. 2015;150:299-307.
34. Rothe F, Laes JF, Lambrechts D, Smeets D, Vincent D, Maetens M, et al Plasma circulating tumor DNA as an alternative to metastatic biopsies for mutational analysis in breast cancer. Ann Oncol. 2014;25:1959-65.

35. Bettegowda C, Sausen M, Leary RJ, Kinde I, Wang Y, Agrawal N, et al. Detection of circulating tumor DNA in early- and late-stage human malignancies. Sci Transl Med. 2014;6:224ra224.

36. Dawson SJ, Tsui DW, Murtaza M, Biggs H, Rueda OM, Chin SF, et al. Analysis of circulating tumor DNA to monitor metastatic breast cancer. N Engl J Med. 2013;368:1199-209.

37. Murtaza M, Dawson SJ, Tsui DW, Gale D, Forshew T, Piskorz AM, et al. Non-invasive analysis of acquired resistance to cancer therapy by sequencing of plasma DNA. Nature. 2013;497:108-12.

38. Heidary M, Auer M, Ulz P, Heitzer E, Petru E, Gasch C, et al. The dynamic range of circulating tumor DNA in metastatic breast cancer. Breast Cancer Res. 2014;16:421.

39. Gobel G, Auer D, Gaugg I, Schneitter A, Lesche R, Muller-Holzner E, et al. Prognostic significance of methylated RASSF1A and PITX2 genes in blood- and bone marrow plasma of breast cancer patients. Breast Cancer Res Treat. 2011;130:109-17.

40. Yamamoto N, Nakayama T, Kajita M, Miyake T, Iwamoto T, Kim SJ, et al. Detection of aberrant promoter methylation of GSTP1, RASSF1A, and RARbeta2 in serum DNA of patients with breast cancer by a newly established one-step methylation-specific PCR assay. Breast Cancer Res Treat. 2012;132:165-73.

41. Fujita N, Nakayama T, Yamamoto N, Kim SJ, Shimazu K, Shimomura A, et al. Methylated DNA and total DNA in serum detected by one-step methylation-specific PCR Is predictive of poor prognosis for breast cancer patients. Oncology. 2012;83:273-82.

42. Van der Auwera I, Elst HJ, Van Laere SJ, Maes H, Huget P, van Dam P, et al. The presence of circulating total DNA and methylated genes is associated with circulating tumour cells in blood from breast cancer patients. $\mathrm{Br}$ J Cancer. 2009;100:1277-86.

43. Fiegl H, Millinger S, Mueller-Holzner E, Marth C, Ensinger C, Berger A, et al. Circulating tumor-specific DNA: a marker for monitoring efficacy of adjuvant therapy in cancer patients. Cancer Res. 2005;65:1141-5.

44. Avraham A, Uhlmann R, Shperber A, Birnbaum M, Sandbank J, Sella A, et al. Serum DNA methylation for monitoring response to neoadjuvant chemotherapy in breast cancer patients. Int J Cancer. 2012;131:E1166-72.

45. Martinez-Galan J, Torres-Torres B, Nunez MI, Lopez-Penalver J, Del Moral R, Ruiz De Almodovar JM, et al. ESR1 gene promoter region methylation in free circulating DNA and its correlation with estrogen receptor protein expression in tumor tissue in breast cancer patients. BMC Cancer. 2014;14:59.

46. Hagrass HA, Pasha HF, Ali AM. Estrogen receptor alpha (ERalpha) promoter methylation status in tumor and serum DNA in Egyptian breast cancer patients. Gene. 2014;552:81-6.

47. Fu D, Ren C, Tan H, Wei J, Zhu Y, He C, et al. Sox17 promoter methylation in plasma DNA is associated with poor survival and can be used as a prognostic factor in breast cancer. Medicine (Baltimore). 2015;94:e637.

48. Chimonidou M, Strati A, Malamos N, Georgoulias V, Lianidou ES. SOX17 promoter methylation in circulating tumor cells and matched cell-free DNA isolated from plasma of patients with breast cancer. Clin Chem. 2012;59:270-9.

49. Bodenstine TM, Seftor RE, Khalkhali-Ellis Z, Seftor EA, Pemberton PA, Hendrix MJ. Maspin: molecular mechanisms and therapeutic implications. Cancer Metastasis Rev. 2012;31:529-51.

50. Sharma G, Mirza S, Parshad R, Srivastava A, Gupta SD, Pandya P, et al. Clinical significance of Maspin promoter methylation and loss of its protein expression in invasive ductal breast carcinoma: correlation with VEGF-A and MTA1 expression. Tumour Biol. 2011;32:23-32.

51. Guerrero-Preston R, Hadar T, Ostrow KL, Soudry E, Echenique M, lli-Gangas C, et al. Differential promoter methylation of kinesin family member 1a in plasma is associated with breast cancer and DNA repair capacity. Oncol Rep. 2014;32:505-12.

52. Sturgeon SR, Balasubramanian R, Schairer C, Muss HB, Ziegler RG, Arcaro KF. Detection of promoter methylation of tumor suppressor genes in serum DNA of breast cancer cases and benign breast disease controls. Epigenetics. 2012;7:1258-67. 